Instructions for authors, subscriptions and further details:

http://qre.hipatiapress.com

\title{
Understand Sexual Risk Behaviours in Young Adults and Challenges in their Education
}

Laura Alonso-Martínez ${ }^{1}$, María Fernández-Hawrylak ${ }^{1}$, Davinia HerasSevilla $^{1}$ \& Delfín Ortega-Sánchez ${ }^{1}$

1) Department of Educational Sciences, University of Burgos, Spain.

Date of publication: June $28^{\text {th }}, 2021$

Edition period: June 2021 - October 2021

To cite this article: Alonso-Martínez, L., Fernández-Hawrylak, M., HerasSevilla, D., \& Ortega-Sánchez, D. (2021). Understand Sexual Risk Behaviours in Young Adults and Challenges in their Education. Qualitative Research in Education, 10(2), 172-203. doi:10.17583/qre.2021.6996

To link this article: $\mathrm{http}: / / d x . d o i . o r g / 10.17583 / q r e .2021 .6996$

\section{PLEASE SCROLL DOWN FOR ARTICLE}

The terms and conditions of use are related to the Open Journal System and to Creative Commons Attribution License (CC-BY). 


\section{Understand Sexual Risk Behaviours in Young Adults and Challenges in their Education}

Laura Alonso-Martínez

Universidad de Burgos

Davinia Heras-Sevilla

Universidad de Burgos
María Fernández-Hawrylak

Universidad de Burgos

Delfín Ortega-Sánchez1

Universidad de Burgos

(Received: 05 November 2020; Accepted: 25 June 2021; Published: 28 June 2021)

\section{Abstract}

Sexual risk behaviours are considered sexual conducts that can cause biological, psychological and social damage. Therefore, sexuality education is considered the only effective way to avoid it. This project aims to understand sexual risk behaviour factors and their consequences in young adults and to explore strategies they would use to face them. To answer these questions, we conducted a qualitative study in which we interviewed 11 young adults using an asynchronous mail technique due to the Covid19 pandemic. We also carried out a thematic analysis and developed our key results: 1) Sexual attitudes and behaviours; 2) Sexual risk factors, 3) Sexual risk consequences; and 4) Educational approach and strategies. Similarities in the themes were verified with previous literature, exposing the importance of learning to identify factors and consequences to respond appropriately. Participants believe that comprehensive and egalitarian sexuality education applied at individual and community level is a solid method that can improve sexual health and well-being. To conclude, this study reveals the importance of listening to young adults' perspectives towards these conduct variables and educational approaches in order to establish global health strategies that could be based on these results.

Keywords: consequences, sexual attitude, sexual behaviour, sexuality education, risk factor, young adult 


\section{Comprender las Conductas de Riesgo Sexual en Adultos Jóvenes y los Desafíos en su Educación}

Laura Alonso-Martínez

Universidad de Burgos

Davinia Heras-Sevilla Universidad de Burgos

\author{
María Fernández-Hawrylak \\ Universidad de Burgos \\ Delfín Ortega-Sánchez1 \\ Universidad de Burgos
}

(Recibido: 05 de noviembre de 2020; Aceptado: 25 de junio de 2021; Publicado: 28 de junio de 2021)

\section{Resumen}

Las conductas de riesgo sexual se consideran conductas sexuales que pueden causar daños biológicos, psicológicos y sociales. Por lo tanto, la educación sexual se considera la única forma efectiva de evitarla. El objetivo de este estudio cualitativo es comprender los factores de las conductas sexuales de riesgo y sus consecuencias en los adultos jóvenes y explorar las estrategias que utilizan para enfrentarlos. Se entrevista a 11 adultos jóvenes utilizando la técnica de correo asincrónico debido a la pandemia de la Covid19. Se desarrollan los resultados clave a través de un análisis temático: 1) Actitudes y comportamientos sexuales; 2) Factores de riesgo sexual; 3) Consecuencias de riesgo sexual; y 4) Enfoque y estrategias educativas. Las similitudes de los temas se verificaron con la literatura previa, exponiendo la importancia de aprender a identificar factores y consecuencias para responder adecuadamente. Los participantes creen que la educación sexual integral e igualitaria aplicada a nivel individual y comunitario es un método sólido que puede mejorar la salud y el bienestar sexual. Este estudio revela la importancia de escuchar las perspectivas de los adultos jóvenes sobre estas variables de conducta y enfoques educativos para establecer estrategias globales de salud que podrían basarse en estos resultados.

Palabras clave: adulto joven, consecuencias, comportamiento sexual, educación sexual, factor de riesgo 
exuality is a main aspect of being human and it can be considered the experience of being sexed, formed by biological, psychological, and sociocultural variables such as sex, gender, sexual orientations, pleasure, and socio-affective relationships. It is also influenced by political, economic, and historical dimensions (Simon, 2017). Human sexual development is bounding to the life experiences and it is exhibited through attitudes, behaviours, beliefs, roles, fantasies and desires (Cacciatore et al., 2019).

This conception is ratified in the current WHO definition of sexual health as " $a$ state of physical, emotional, mental and social well-being in relation to sexuality" (WHO, 2006, p.5). This definition does not focus solely on preventing the transmission of sexual diseases, but is capable of holistically encompassing the understanding of lived experiences; the importance of guaranteeing freedom, security and respect for sexuality; and the search for international organizations that protect sexual health by ensuring the fulfillment of universal sexual rights (Schick et al., 2010). In the international context, investment in and promotion of sexual health, sexual education and gender equality are increasingly important (UNESCO, 2018).

Nowadays, World Association for Sexual Health (WAS) and United Nations approved in 2014 the Universal Declaration of Sexual Rights, among which we would like to emphasize those based on nondiscrimination or the right to education and health (WAS, 2014). Hence, people have the right to live a healthy sexuality, fulfilling the duty to respect others. These universal rights and duties are protected by different world health organizations and must be the benchmark by which local, national, and international institutions are guided to guarantee social welfare (UNESCO, 2018). Nevertheless, the proper way to evaluate these sexuality experiences is through the sexual attitudes and behaviours exhibited (Cacciatore et al., 2019).

\section{Background}

\section{Sexual Attitudes and Behaviour}

Attitudes towards sexuality are sexual predispositions developed throughout life experiences and sociocultural norms, composed of affective, 
cognitive and behavioural traits (Lin \& Lin, 2018). Sexual positive dispositions are known as erotophilic attitudes and, conversely, the negative dispositions are known as erotophobic (Balzarini et al., 2020). Presently, some of the most negative sexual attitudes are sexism, homophobia, and transphobia. Consequently, sexual behaviour is the action conducted based on the cognitive and affective evaluation of sexuality (Hubert et al., 2020). Thus, to change negative sexual behaviours it is necessary to involve the corresponding attitudes. These constructs have been researched at different stages and social groups with special incidence in adolescents and vulnerable collectives. However, in order to develop ecological validated interventions, it is essential to consider factors from different life stages, such as early years and professional training (Walker, 2014).

\section{Sexual Risk Behaviour and Educational Approach}

Sexual risk behaviours are sexual conducts that can cause physical, psychological and/or social harm (Meader et al., 2016). The most studied ones have been biological behaviours related to Sexually Transmitted Infections (STIs), unprotected sex, premature sexual relationship, or unwanted pregnancy (Benotsch et al., 2013). However, WHO (2019) has explained that strategies conducted to avoid these behaviours are insufficient due to it estimates that more than 1 million STIs are acquired every day. These diseases are mostly transmitted by risky sexual contact (vaginal, anal, and oral) without using condom as a protective barrier method (WHO, 2019). For instance, Kann et al. (2018) evaluation within the CDC (Centers for Disease Control and Prevention) showed that the prevalence of sexual risk behaviour in the United States is present in 55\% of the population. These results would be related as well to data obtained by the WHO (2019), the CDC (2016) and the Public Health Agency of Canada (2015), which detected an increase in STIs and sexual risk behaviours among the population. Nevertheless, the European ratio of new cases of HIV in Europe per 100,000 inhabitants is 5.1 and it has been decreasing between 2009 and 2018, and this is also the case for Spain and the United Kingdom, although both countries have higher ratios (6.4 and 6.7 respectively) than the European average (European Center for Disease Prevention and Control, 2019). 
Hence, their factors are varied and complex to analyse, including sociocultural, generational, knowledge, attitudinal and personal variables (Benotsch et al., 2013), such as those listed in Table 1.

Table 1.

Factors influencing risk behaviours and their consequences ${ }^{1}$

\section{Variables Risk behaviours factors and consequences}

Sociocultural Sexual discrimination and violence in favour of heteropatriarchy and heteronormativity.

Greater adherence to male roles associated with higher risk behaviours.

Oversexualization in the media.

Lack of education and egalitarian healthcare by social group and country.

Dysfunctional families, insecure attachment related to sexual risk.

Generational

Initiation of negative attitudes and behaviours.

Childhood Pressure on first sexual encounter and negative vision towards and

adolescence Feeling of power and impunity when believing that they know more due to its easy access through Internet.

Adulthood Looking for partner satisfaction.

Maintaining toxic conducts and jealousy as a positive aspect.

Undesirable pregnancies and infertility.

Vulnerable Adolescents, people from the LGTBIQ+ Community, disabled, groups elderly, drug addicts and sex workers Greater presence of unfairly negative sexual stereotypes.

Sexuality invisibility of disabled and elderly.

Individual Culture (religion), age, sex, and gender.

Personality: good emotional control associated with lower sexual risk behaviours.

Alcohol and drug consume. 
Finally, there are different factors that increase sexual risk behaviours and have psychological, biological, and social consequences (Schick et al., 2010). The content taught in sex education is highly variable worldwide. The International Conference on Population and Development has repeatedly called on governments to improve equitable access to health and education programs. These existing inequalities by country continue to be marked and negatively influence the health of their residents. In low- and middle-income countries, sex educational measures are in some cases nonexistent, continue to be subject to policies of sexual abstention or based on the religious morality of nations that has prevailed, compared to more professionalized and individualized approaches, althought its main purpose of these strategies is usually to prevent STIs (Meader et al., 2016).

Several studies support that Sexuality Education through a biographical and professional model is the most feasible method available to guarantee significant positive changes towards healthy sexual experiences (Grose et al., 2014). Educational proposals from this approach should start from the population analysis of sexual knowledge, attitudes, and behaviours to conduct integrative and transversal interventions that are individually and collectively appropriate from a perspective focused on Global Health (Jamison et al., 2013). These programs also must be contextualized at a sociocultural level and ensure the promotion and recognition of human sexual rights (European Expert Group on Sexuality Education, 2016).

\section{Research Gap}

Young adults (19 to 39 years) can inform about their sexual behaviours from a retrospective view after their transition from adolescence to adulthood, and they can also reflect on their sexual initiation conducts with greater maturity, evaluating their strategies to reduce these behaviours (Lambie \& Price, 2015). Additional long-term knowledge of their sexual life can be identified through their professional practice or the behaviours transmitted to their offspring. According to WHO (2019), educational strategies are insufficient because they are subject to the sociocultural norms and negative preconceptions of sexual intercourse such as the sin, as consequence, these conducts are globally increasing, and young adults have a higher prevalence of unprotected sex and STIs. Despite substantial amount of research focused on evaluating conducts of adolescents and their 
families, we cannot fully identify sexual risk behaviour without understanding young adult views (Cook et al., 2016). Nonetheless, most of these studies follow a quantitative method, showing a limitation in their indepth exploration (Kjellgren, 2019). Thus, this project is based on an epistemological theory, as it identifies opinions about sexual risk behaviour in young adults from different countries. The theory is underpinned in constructivism, which explains that reality depends on its social construction and it can be associated in multiple ways with cultural perspectives (Pringle et al. 2016).

Therefore, in this study, we explore risk behaviours in young adults who have already had sex, asking about factors, consequences, and strategies (mean making). The aim is for us to obtain a deeper understanding of factors and consequences of sexual risk behaviours views in young adults and to explore the educational approaches they would use to prevent it. With that in mind, we developed the research questions: What are the risk factors that influence the performance of sexual behaviours that are harmful to health?, what are the consequences derived from such risk behaviours?, what is the meaning that young adults give to sexual behaviours? and what strategies would young adult use to prevent these behaviours?

\section{Materials and Methods}

\section{Approach}

An empirical phenomenological qualitative approach is adopted to develop a shared description of the essence of the participants' experience (Hernández et al., 2014). To resolve these research questions, as it allows us to collect information, to identify actions of our own reflexivity and to assume human development in a sociocultural context (Nadal et al., 2015). This approach allows us to understand people from a perspective focused on their context, guaranteeing a direct exchange between researcher and participants and contributing to building knowledge in sexual behaviour (Braun \& Clarke, 2019). 


\section{Participants}

We recruited 11 participants between 21 to 38 years (mean=28.5, $S D=5.46$ ), of whom 9 were females and 2 males (opportunity sample). Their gender identity was cisgender and their sexual orientation was heterosexual. Interviewees needed to be young adults, to have had sexual intercourse and to come from different sociocultural contexts to analyse in depth more heterogeneous cultural samples. Another requirement was to speak English. All these requirements are important because the sexual experience that these young adults have had allows us to understand how risky sexual behaviours are understood and dealt with in an individual way and consider how they have been influenced by certain educational contexts in different countries. Table 2 summarises participant demographic information, and relevant variables from the study. For anonymity, all participants' names have been replaced to safeguard their confidentiality.

Table 2.

Participant demographics and personal details $(n=11)^{2}$

\begin{tabular}{llllccc}
\hline Name & Sex & Age & Nationality & $\begin{array}{c}\text { Marital } \\
\text { status }\end{array}$ & Religion & Occupation \\
\hline Jane & Female & 32 & Bulgarian & Married & Orthodox & $\begin{array}{c}\text { Psychologist/ } \\
\text { postgraduate/mother }\end{array}$
\end{tabular}

Alice Female 30 Czech Cohabitation Agnostic Innkeeper/postgraduate

Chloe Female 31 Japanese Married Shintoism Waitress/student/mother

Katie Female 23 British Single Orthodox Teacher/postgraduate

April Female 28 Egyptian Married Islam Psychologist/

postgraduate/mother

Dana Female 38 Chinese Married Agnostic Lawyer/Mother

Rachel Female 21 Indian Single Taoism Counsellor/postgraduate

Ruth Female 25 Spanish Cohabitation Catholic Nurse/postgraduate

Johana Female 24 Vietnamese Single Buddhism Biotechnology/

postgraduate

Daniel Male 36 Spanish Married Catholic Counsellor/father

Mark Male 25 Spanish Cohabitation Catholic Videogame programer 


\section{Procedure}

This study was carried out in Newcastle Upon Tyne (UK) and the samples were collected by one of the main researchers taking advantage of the fact that she was doing a research stay in that city. The researchers found it enriching and a great opportunity to be able to conduct interviews in a context with such cultural richness, not present in their locality of origin. Sexual behaviours, as opposed to attitudes, have been considered similar in different cultures and hence the researchers interest to analyse in this sample. The study was favorably reported by the Northumbria University ethics committee and data was collected during spring of 2020. The sample participants were obtained via announcement at the university where the study was approved and at Newcastle Council adult schools. Once interviewees agreed to participate, they were contacted by phone to explain the study and to resolve any question, then the researchers sent an email with the participant and debrief sheet and interview questions (Annex 1) to those participants who met the requirements. The interviewees who voluntarily decided to participate sent us the responses and their signed consent forms. The emails were sent to 20 possible participants, of which 7 answered in the first round, after which a second round of emails was sent, only receiving 3 responses. Finally, only 1 participant answered in the last round.

Therefore, an interview guide was designed to explore their approach towards sexual behaviours. This guide was structured into the ensuing sections: 1) Demographic information; 2) Sexuality Knowledge; 3) Factors and consequences approaches of sexual risk behaviour; and 4) Strategies to prevent it. The interviews lasted approximately one hour, as the researcher asked the participants to report how long it took them to complete. The data collection, due to COVID-19 situation, was gathered through asynchronous email interview, since all the participants, except one, did not speak English as a mother language, so they felt less shame and more comfortable responding the interviews in writing (Ratislavová \& Ratislav, 2014). Considering the context and that written answers allow the interviewee to have more time flexibility and feel more confident about this controversial topic, it was decided to do all the interviews following this technique to give conformity to the collection (Opdenakker, 2006). This data collection technique is constrained in obtaining information through non-verbal and 
paralinguistic language (Meho, 2006). Hence, to overcome these limitations, participants were asked to give us feedback on how they felt during its performance and they could ask questions; this information was added to analysis data (Ratislavová \& Ratislav, 2014).

\section{Data Analysis}

All interviews were transcribed by the participants and collected through the researcher emails and then, a thematic analysis was conducted using the AQUAD program. The thematic analysis used in this study has a constructionist approach focused on the way in which topics have been build (Clarke \& Braun, 2014). However, this analysis has also had an experiential perspective, because it aims to capture experiences and perspectives of how participants feel. The researchers developed an initial coding framework based on the dataset reflection and the analysis of previous literature. Hence, data were interpreting using the 6 stages of codification by Braun and Clarke (2006). The author familiarised with the data, through an intensive reading and rereading, facilitating the understanding of the transcript's information. This actively allowed initial codes to be generated thanks to the comparison between the collected data from which repeated information patterns appeared. Before obtaining higher order codes from our final topics, these were reviewed and refined with the general dataset. Then, once these final themes were identified, this process involved reviewing, defining and naming the themes and finally producing the report (Braun \& Clarke, 2019). The topics obtained were agreed upon by all the researchers. To improve reliability, themes and codes were monitored closely during its process (Guest et al., 2012). This process has the benefit of granting flexibility and was suitable for analysing the data (DeCuir-Gunby et al., 2011). The focus of this analysis was on how young adults had a decisive vision towards the factors and strategies to reduce risk behaviours. This final analysis led to the development of our key results explained below.

\section{Results}

Our analysis revealed a large amount of important approaches in which young adults understand sexual risk behaviours, but more significantly 
shows how to help develop strategies to avoid these conducts. We reflected and presented our key results under these four sections: 1) Sexual attitude and behaviour (Key concept definition); 2) Sexual risk behaviour factors (Multiple variable approach), 3) Sexual risk behaviours consequences (Biological, psychological and sociological) and 4) Educational approach and strategies (methodology and tactics). These themes and subthemes categorisations were obtained inductively during the analysis and represented the dataset, see Table 3. Overlapping themes were also interpreted based on the stage that we felt was most suitable. Each theme had implications about adults' perspectives on these behaviours, addressed below. To understand the complex relationship between sexual risk behaviours showed in this table, a thematic map (Figure 1) has been designed to expose the link and influences between these conducts.

Table 3.

Themes and subthemes ${ }^{2}$

\begin{tabular}{|c|c|}
\hline Themes & Subthemes \\
\hline $\begin{array}{l}\text { 1) Sexual } \\
\text { attitude and } \\
\text { behaviour } \\
\text { knowledge }\end{array}$ & $\begin{array}{l}\text { Attitude definition. } \\
\text { Behaviour definition. } \\
\text { Sexual risk behaviour definition. } \\
\text { Relationship between the terms }\end{array}$ \\
\hline $\begin{array}{l}\text { 2) Sexual risk } \\
\text { behaviour } \\
\text { factors. }\end{array}$ & $\begin{array}{l}\text { Generational and ages: } \\
\text { Adolescent and young people more vulnerable. Lack of maturity. } \\
\text { Peer pressure (friends and partners). } \\
\text { Social media and easy access to knowledge by Internet. } \\
\text { Curiosity for sexual experiences. } \\
\text { Multiple partners. } \\
\text { Sex, gender, and sexual orientation: } \\
\text { Men more sexual risk behaviour, not worried about pregnancy. } \\
\text { Gender differences in sexual pleasures. } \\
\text { Social norms. Heteropatriarchy and heteronormative (Sexism, } \\
\text { gender violence, Homophobic and Transphobic). } \\
\text { Sociocultural: } \\
\text { Historical social change of the sexual norms. }\end{array}$ \\
\hline
\end{tabular}


Table 3.

Themes and subthemes (continuation)

\section{Themes Subthemes}

2) Sexual risk Lack of resources.

behaviour Lack of education. Not understanding the contraceptives target.

factors. Inequalities by country and status.

Environment around, friends, neighbourhood.

Negative vision about fantasies, masturbation, and sexuality.

Personal factor (Individual):

Life experiences. Fun life

Human existential crisis.

Beliefs. Fear to be punished by God (Hell).

Personality. Low esteem. Emotional control

Family education and their sexual approach. Dysfunctional families. Mental disorders.

Consumption of drugs and alcohol

Combination (Real context).

3) Sexual risk Biological: STIs, unwanted pregnancy and infertilities.

behaviours Psychological: trauma, humiliation, mental disorder, upbringing consequences. problems, stigma internalised, adolescent mother, feeling worthless, lack of trust in others and being more at risk of mental health conditions.

Sociological: Taboo, lost friends, family, work, sexual illness stigma and prejudice, education (more conservative more restrictions), strict sociocultural norms, serial monogamy is accepted, sexual abuse, gender violence, kid responsibility and maintaining of heterosexist norms 
Table 3.

Themes and subthemes (continuation)

\begin{tabular}{ll}
\hline Themes & Subthemes \\
\hline 4)Educational & Educational approach: Combination between parents, community, \\
and strategies & and school education. Scientific approach. Being reactive with the \\
approach & sexual behaviour problems. Integral, holistic and transversal \\
& $\begin{array}{l}\text { approach (biological and psychological transversal). Teaching } \\
\text { factors and consequences. Teaching to use resources in a scientific }\end{array}$ \\
& way. Comprehensive education. Health education must be \\
& compulsive.
\end{tabular}

Strategies:

Government education/Public Health.

Children, adolescent and parent education.

Analyses individually. Individual advice.

Show good role models.

Professional advice. Psychologist, teacher, and doctors.

Reducing sexuality taboo and prejudice against it.

Normalize Sexuality's nature.

Avoid sexuality constraint educator to speak about sexual education.

Try to have a good communication (school, children and parents)

Increase esteem and affection. Psychological education.

Evaluate sociocultural differences.

Social media interventions.

Sexual abuse support and other healthy sexual networks

Reducing sexual risk behaviour through combined intervention in school, parents, and social.

\section{Different educational and strategies perspectives:}

Adolescent education.

Early stage education and continued for life.

Adolescent start and continue at university.

Concern all the population.

Sex education: religious and non-scientific education never in the school/ Teach in a religious moral. 


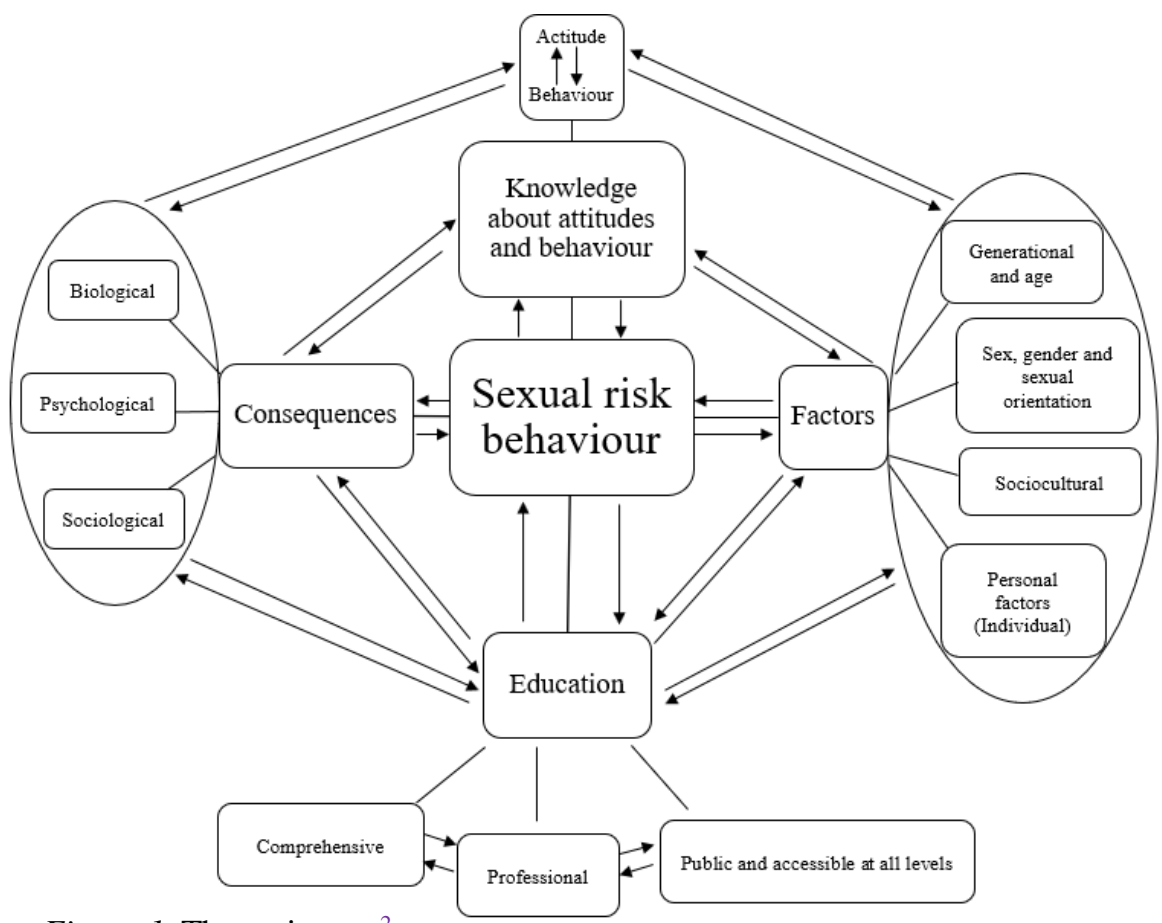

Figure 1. Thematic map ${ }^{2}$

\section{Sexual Attitude and Behaviour}

Overall, we identified that participants understand these terms, except for Jane and Dana who chose not to answer. Interviewees similarly defined sexual attitude such as approaches, opinions and beliefs and behaviour as an act, for example:

"Attitude is a belief that you might have about a certain aspect/thing. Behaviour is an action that may be based on your attitude/belief/desire." (Daniel)

They have also found relationships between these constructs, exposing that behaviours are based on the attitudes, shown below: 
"In my understanding, I think attitude is one's mental perception and opinion towards a social situation, individual etc while behaviour is their physical reaction which may or may not be in response to their attitude. For example, if one's attitude towards homosexuals is negative, they might produce homophobic behaviour towards homosexuals." (Rachel)

Finally, ingterviewee defined sexual risk behaviours as harmful health conducts such a Mark explained:

"A behaviour could imply sexual risk if it can compromise the sexual health, or even the overall health of the person. For instance, having sexual relationships without any contraceptive measure could be dangerous for those participating, including transmitting STDs."

\section{Sexual Risk Behaviour Factors}

Participants showed there are multiples interrelated factors, explained below in four subtopics. However, the most repeated have been the adolescence risk and toxic substances consumption coinciding with social media determinants.

\section{Generational}

Participants explained that generational change has given a greater sexual freedom and increased sexual risk behaviours. However, they added that it was not that the previous generation knew more, but that these conducts were controlled by strict social norms.

"I think older generations generally have the mindset of having one sexual partner and may have married when they were very young so this may decrease the chance of sexual risk behaviour." (Katie)

Moreover, adolescents and young people are considered the most vulnerable group because they are in a maturity stage. Interviewees explained that these groups are exposed to greater group pressures (virginity lost), drug consume and Internet overexposure: 
"Being under the influence of alcohol or substances also can put one at risk of sexual behaviours due to the level of fluctuating capacity and engaging in acts one would not if sober. Pressure from society and friends can also influence one's behaviour towards engaging in risky sexual behaviour. I believe that younger people from late teenage and early 20s are more likely to be "adventurous" and engage in sexual risky behaviour than mature people." (Daniel)

"I think adolescent girls are particularly at risk due to peer pressure. Internet use is more common amongst adolescents and girls may turn to the internet to seek advice and this may not be the right advice for their age, or they may be at risk of seeing content that is not age-appropriate". (Katie).

\section{Sex, gender and sexual orientation}

Participants considered that women are more vulnerable (sexist societies) and explain that they seek to please men. For example, they exposed an idea that men have less pleasure with condoms and women use contraceptives to satisfy them and to protect against the pregnancy:

"So, with them, if they think pleasure comes first or think women should always have contraceptive pills with them, then they may be don't want to use the condom anymore. I heard men think it can compromise their pleasure. Hmmm....about women, I think many women feel that if they ask for protection during sex, they will risk upsetting their partners, at least in Asia I think this quite common, so they will follow their partners' suggestion. I think most of women still choose to address pregnancy by themselves by using contraceptive products." (Johana)

"I believe men may be less concerned about consequences since they cannot get pregnant, in many cases not assuming responsibilities related with undesired pregnancies." (Mark)

Participants exposed that sexist attitudes are decreasing, although they emphasize their existence. Interestedly, an interviewee explained the 
existing masculinized vision in making female sexuality invisible and controlled:

"And nowadays if you suffer sexual abuse and gender violence (sexism) most of the countries punish that. However, women enjoy the same during sexual intercourse without preservative, because they have pleasure in the clitoris." (Ruth)

Another aspect recognized by the participants was that LGTBIQ+ community is vulnerable to this risk due to heterosexist attitudes:

"I think people who are considered as sexual minorities are more likely to engage in sexual risk behaviours. For example women and people from the LGBTQ+ communities." (Rachel)

\section{Sociocultural factor}

In this categorization, participants included health and education inequalities between countries and status. They also explained the influence of the environment and religion:

"It could happen when people don't get adequate education about the risk or simply, it could just happen in poor communities/countries as they might find hard to gain materials (eg, sexual protection) to protect them from sexual diseases or to prevent having unwanted child.“ (Cloe)

\section{Personal factors}

Interviewees highlighted personality traits and mental health conditions that influenced the emotional positive control and self-esteem:

"It has a lot of factors, like taking drugs, drinking a lot of alcohol or also disorders like a disorder in their personality or even a mental disorder. If the mother and father have disorders, they might have an impact on their children." (April)

"Predatory sexual approaches by older men who prey on vulnerable, younger women (teenagers and young adults). I think this happens a lot all over the world but especially in poorer 
countries, where money is means of coercing young women into relationships and sex." (Jane)

Another aspect indicated was lived experiences such as crises, dysfunctional families or drug use, among others:

"Or even older people if they are facing any crises divorces or something they may act a bit silly." (Alice)

"I think people who engage in risky sexual behaviour from a young age may have a lack of social/family support and may not feel able to speak to anyone about what is acceptable and so they are more vulnerable to peer pressure." (Katie)

\section{Sexual Risk Behaviours Consequences}

Participants have expressed the sexual risk behaviour consequences in three different dimensions being biological, psychological and social. At biological, they mentioned the STIs, unwanted pregnancy and infertilities:

"Physiologically, may be infected with STD, pregnancy for women, even cause fertility problem in the future. Psychologically may cause trauma." (Dana).

At a psychological level, the impact described by the interviewees is very varied, exposing the possible development of mental health conditions based on lived experiences (sexual abuse, unwanted motherhood, sexual illnesses stigma or having unhealthy relationships), that will affect the sexual development. Moreover, they considered that social networks can contribute to increase humiliation and trigger depression and even suicide:

"Aw that's a lot I think. So many diseases and mental health problems as well as humiliations. Unfortunately, there is so much these days that people can get from people by having sex. And people talk about it on social media at school and I don't know where else which affects one's mental health and then people laugh at you and I have seen people committing suicides because they coudnt take it. So it could have so many bad effects." (Alice). 
"Psychological consequences: low self-esteem, feeling worthless, lack of trust in others and being more at risk of mental health conditions." (Daniel).

At a social level, interviewees referred to heterosexist behaviour maintenance, taboo, and stigmatization of sexual behaviours and diseases. They also explained that the repercussion of these behaviours could cause friendship and job loss:

"I think sexual risks are a highly prejudiced issue which does not have enough discussion in daily conversation. I think sexual risks should not be treated with that kind of prejudice and stigma." (Rachel).

"Stress, traumatic life, and people talk...so on. It can ruin many things, like self-esteem, or career, or future...It can damage relationships with friends and family as well. Hmm....and of course, you can get some disease via intercourse too but I think many people neglect that fact." (Johana).

\section{Educational and Strategy Approach}

Most of the participants believed in a comprehensive and professional educational approach between the school, community and family. They also believed that sexuality education must include biological, psychological and sociological perspectives and to teach how to use the available resources, such as Internet:

"There should be educational programs in schools, in the community and at a family level to help address such behaviour. The optimal age should be informed by research and the county or region-specific data." (Jane).

"I think the education when I was at school and now are different, but sexuality education needs to cover how sexual risk behaviour will affect people's life physically, mentally and financially." (Cloe). 
The most considered strategy was providing public sexual education to children, parents and educators. Furthermore, they explained that individual perspectives and professional advice are necessary. They suggested the sexuality process must be naturalised and reduce its prejudices. They also indicated that an education based only in biological aspects is not enough, sociocultural and psychological variables should be added:

"My advice would be to move forward, ty to analyse what exactly went wrong and avoid the same mistakes. To be a good role model and influence other people who might be prone to face sexual risk behaviour" (Jane).

"For my opinion, the most important thing is to understand and communicate more with adolescent children in the family. Sex is a normal physiological need, do no avoid talking about this topic with them. We should help them better to understand sexual knowledge, sexual safety education and the serious consequences of sexual risks." (Dana).

"I think that we must give more a psychological approach because the attitude and behaviour are mental things. You should speak with a professional that can help you and always you must think in your safety and in yourselves" (Ruth).

Finally, we found participants discrepancies regarding the start of sexual education, some participants considered that it was necessary to start it as early as possible and others from adolescence, but all believed that it should be continued for life:

“As early and naturally as possible. It doesn't necessarily need to be in an educational setting as parents or guardians of the children have a crucial role to protect their children from the risk behaviour too" (Cloe)

"Probably around 15-16 because they start exploring and going out and drinking and so they need to know how bad it can be. Definitely at school would help however that could have bad effect as well cause if you talk in front of everyone, they will al laugh and so. So maybe somehow individually if possible. Or parents could 
tell them or groups at school only like 5-6 people so they can have proper conversations about it and ask questions" (Alice).

"I think theses programs should be taught at all of the ages however, adolescence age might have the most effect for this behaviour." (April).

However, other controversially topic was religious sex education explicitly reject or accept as appropriate:

"I would try to avoid trusting in educators that show biases (religious, political...etc.) as their views will probably conflict with proper educational values". (Mark).

"Humanitarian/religious lessons which emphasise importance of sex and its significance" (Daniel).

\section{Discussion}

The study began with a focus on understanding sexual attitudes and behaviours in young adults to answer the research questions. Firstly, we talked about key sexual behaviour terms from an approach focused on addressing how they build their knowledge towards the sexual constructs that guide their behaviour (Hubert et al 2020). Participants explained attitude as a predisposition and behaviour as an act, connecting these terms by understanding that attitudes toward sexuality determine behaviours. These conceptualizations are similar to those interpreted by Lin and Lin (2018). However, most of the studies focused on studying sexual risk without delving into the terminology preconception, not considering that it cannot initiate behavioural change if these assumptions are not recognised (Kaufman et al., 2019). Sexual risk behaviours were identified as harmful conducts and related mainly to drug use, adolescence, and STDs, coinciding with the most media factors (Wagenaar et al., 2018). Nevertheless, with the same age and educational level as in our sample, greater sexuality knowledge is assumed due to the experiences lived (Hubert et al. 2020). For that reason, we identified understanding inequality of these concepts among participants (Walker, 2014). 
Secondly, in the second and third themes identified, participants have explicitly answered the first research question. During the data analysis, the complexity of the topic and the similarities of perspectives between participants from different ages and sociocultural backgrounds was fairly surprising. Consequently, the most identified sexual risk factors were age, sex, sociocultural experiences and personality, coinciding with the themes identified in the study in young adults of Wagenaa et al., (2018). Sexual behaviour is stable across generations, but the degree of social pressure to conform to norms is constantly changing, a vision that was shared by the participants (Comfort, 1990). Nonetheless, adolescence was understood as the transition to adult sexual behaviours (Kjellgren, 2019). This subtheme and the harmful peer influence (negative social pressure from family, friends and/or couple) is shared with the study by Ndumiso et al., (2016). Nevertheless, focusing only on adolescence and forgetting other life stages was considered a social risk factor (Walker, 2014). Therefore, these findings suggest a maintenance of sexual prejudices. For instance, stereotypical male sexuality extolls these conducts, encouraging men to have more partners, be unfaithful and seek his sexual self-satisfaction (Pringle et al., 2017).

At a socio-cultural level, according to the WHO (2019), the most vulnerable populations continue to be women, children, people from LGTBQ+ community and drug users. In relation to this subtheme, the negative impact on sexuality due to inequalities by country and status have emerged in the study (Ndumiso et al. 2016). As predicted from previous literature, there has been an invisibility of sexuality in disability and old age and also a lack of knowledge about erotophilic sexual satisfaction (Balzarini et al., 2020). Finally, personal factors are difficult to assess since they are influenced by individual lived experiences, biological, psychological and social variables (Wagenaar et al., 2018). Participants recognized the relationship between factors and their biological, psychological, and social consequences (Lawal \& Olley, 2017). However, the key aspect that emerged from this study is the explicit explanation of stigma and taboo towards these behaviours, tending to blame and marginalize the people who suffer from it (Mudhovozi, 2011). A high knowledge level about factors and consequences of sexual risk behaviours was appreciated, but this training may not be enough if people do not 
recognise how to identify them in order to respond appropriately (Ndumiso et al., 2016).

Our last theme responds to the second research question in which participants have explained strategies to prevent these behaviours. Interviewees have explicitly proposed the necessity of a comprehensive sexuality education at cognitive, social and psychological level during the sexual development (Stevens et al., 2013). In this sense, themes identified coincided with those of the study by Paiva and Silva (2015) in which it was found that young people recognised the need for more sexuality training not only focused on a clinical content, requesting psychological perspective and the respect for rights and duties. Therefore, young people realize that they need more knowledge about healthy sexual relationships (Wagenaar et al., 2018). Some participants are also parents, thus they highlighted a comprehensive education that includes parents, community and the school (Steadman et al., 2014). Another emerging idea to end inequalities is the consideration of an accessible professional biographical education based on care at an individual and social level (Castillo et al., 2018). There is a worldwide debate on its implementation and the models to follow, such as those proposed by the participants. However, sexuality education is increasingly considered as a priority, adapted to the sociocultural context, regulated in the curriculum, implanted at an early age, continued for life and away from religious morals, focusing on respect for Human Rights (Parker et al., 2009).

Finally, sexual risk behaviours factors, consequences, and strategies to avoid it are explored in a more realistic way, being able to identify explicit information that was limited with quantitative scales (Wagenaar et al., 2018). Hence, the study showed that the participants reflected and wanted to become more aware of issues related to their sexuality and education, which may lead to awareness about these issues (Mudhovozi 2011). From the project's point of view, we are asking ourselves if the majority model of quantitative evaluation towards sexual risk behaviour and strategies are the most appropriate, since a combined approach is needed to make sex education a priority that listens to young adults's needs and improves their sexual health and well-being.

Study strengths contributed to the understanding and construction of information about risky sexual behaviours in young adults, and these findings can be used as resources to establish educational strategies. 
Participants stressed that it is important to end inequalities in access to health and education. They also consider it necessary to implement a comprehensive professional education at all levels, coinciding with results evaluated in the previous literature. Furthermore, to establish credibility by using the written data collection technique, participants have checked their transcripts (Lincoln \& Guba, 1985). Finally, the data analysis followed the stages of Braun and Clarke (2006) recommended for thematic analysis, whereas the interviews were conducted using same technique and in a time period of one month to avoid possible spatial and temporal biases (Ruiz, 2012).

Study limitations are that participants do not represent the general population since they are highly educated people and the majority are studying in the fields of education, psychology or law, being limited to transfer them to other contexts. Also, it does not include sexual minorities views. Sample is not homogeneous by sex and country and would require different participants and new interviews to eliminate these biases (Burns, 2010).

In future studies, it would be necessary to follow these recommendations with a larger number of participants in order to be able to explore the sociocultural differences that help to propose global strategy plans to effectively decrease sexual risk behaviours. In addition, it would be advisable to continue understanding in depth the sexual behaviour trends and their reasons on a personal level and to evaluate the perspectives that sexual minorities have towards these same aspects in order to have a closer vision of reality. Therefore, it would be interesting to use these recommendations to create educational interventions that help develop programs at the local, national and international levels.

\section{Conclusions}

To conclude, knowledge of sexual risk behaviour is mostly positive and high. This study reveals how young adults point to inequalities in their environment, gender and age as main factors. Furthermore, the importance of naturalising sexuality through a comprehensive, public, professional and individually and collectively adapted education that respects human rights. Finally, from these results, social strategies could be developed that consider antecedents of integral sexuality in the sociocultural context. 
In this project, the academic backgrounds of authors play their part. The authors have previously investigated sexual risk, sexual behaviours and attitudes and sexuality education from a quantitative and qualitative perspective. This approach gives researchers a broad and critical vision of the phenomenon to be studied (Hernandez et al., 2014).

\section{Notes}

${ }^{1}$ Own elaboration from Benotsch et al. (2013), Meader et al. (2016) and WHO (2019).

${ }^{2}$ Own elaboration.

\section{References}

Balzarini, R. N., Shumlich, E. J., Kohut, T., \& Campbell, L. (2020). Sexual attitudes, erotophobia, and sociosexual orientation differ based on relationship orientation. The Journal of Sex Research, 57(4), 458469. https://doi.org/10.1080/00224499.2018.1523360

Benotsch E.G., Snipes D.J., Martin A.M., Bull S.S. (2013). Sexting, substance use, and sexual risk behaviour in young adults. Journal of Adolescent Health, 52(3), 307-313.

https://doi.org/10.1016/j.jadohealth.2012.06.011

Braun, V., \& Clarke, V. (2006). Using thematic analysis in psychology.

Qualitative Research in Psychology, 3(2), 77-101.

https://doi.org/10.1191/1478088706qp063oa

Braun, V., \& Clarke, V. (2019). Reflecting on reflexive thematic analysis. Qualitative Research in Sport, Exercise and Health, 11(4), 589-597. https://doi.org/10.1080/2159676X.2019.1628806

Burns, E. (2010). Developing email interview practices in qualitative research. Sociological Research Online, 15(4), 24-35. https://doi.org/10.5153/sro.2232

Cacciatore, R., Korteniemi-Poikela, E., \& Kaltiala, R. (2019). The Steps of Sexuality-A Developmental, Emotion-Focused, Child-Centered Model of Sexual Development and Sexuality Education from Birth to Adulthood. International Journal of Sexual Health, 31(3), 319-338. https://doi.org/10.1080/19317611.2019.1645783

Castillo-Nuñez, J., Derluyn, I., \& Valcke, M. (2018). Young people's expressed needs for Comprehensive Sexuality Education in 
Ecuadorian schools. Sex Education, 18(1), 14-31. https://doi.org/10.1080/14681811.2017.1374941

Centers for Disease Control and Prevention. (2016). Sexually transmitted disease surveillance 2015. U.S. Department of Health and Human Services. https://www.cdc.gov/std/stats

Clarke, V., \& Braun, V. (2014). Thematic analysis. In T. Teo (Ed.), Encyclopaedia of Critical Psychology (pp. 1947-1952). Springer. http://www.springerreference.com/docs/navigation.do?m=Encyclope dia+of+Critical+Psychology+(Behavioural+Science)-book162

Comfort, A. (1990). Has sexual behaviour really changed with time?. Journal of Obstetrics and Gynaecology, 10(5), 351-356. https://doi.org/10.3109/01443619009151215

Cook S.H., Watkins D.C., Calebs B.J., \& Wilson P.A. (2016). Attachment orientation and sexual risk behaviour among young Black gay and bisexual men. Psychology \& Sexuality, 7(3), 177-196. https://doi.org/10.1080/19419899.2016.1168312

DeCuir-Gunby, J. T., Marshall, P. L., \& McCulloch, A. W. (2011).

Developing and using a codebook for the analysis of interview data: An example from a professional development research project. Field Methods, 23(2), 136-155.

https://doi.org/10.1177/1525822X10388468

European Centre for Disease Prevention and Control/WHO Regional Office for Europe. (2019). HIV/AIDS surveillance in Europe 2019-2018 data. https://www.ecdc.europa.eu/en/publications-data/hivaidssurveillance-europe-2019-2018-data

European Expert Group on Sexuality Education. (2016). Sexuality education-what is it?. Sex Education, 16(4), 427-431. https://doi.org/10.1080/14681811.2015.1100599

Goldman, J. D., \& Bradley, G. L. (2001). Sexuality education across the lifecycle in the new millennium. Sex Education, 1(3), 197-217. https://doi.org/10.1080/14681811.2015.1100599

Grose, R. G., Grabe, S., \& Kohfeldt, D. (2014). Sexual education, gender ideology, and youth sexual empowerment. The Journal of Sex Research, 51(7), 742-753.

https://doi.org/10.1080/00224499.2013.809511 
198 Alonso-Martínez et al. - Sexual risk behaviours in young adults

Guest, G., MacQueen, K. M., \& Namey, E. E. (2012). Applied thematic analysis. SAGE Publications.

https://dx.doi.org/10.4135/9781483384436

Hernández, R., Fernández, C., \& Baptista, P. (2014). Metodología de la Investigación (6th ed.). Mc. Graw Hill.

Hubert, M., Bajos, N., \& Sandfort, T. (2020). Sexual behaviour and HIV/AIDS in Europe: Comparisons of national surveys. Routledge.

Jamison, D. T., Summers, L. H., Alleyne, G., Arrow, K. J., Berkley, S., Binagwaho, A., ... \& Ghosh, G. (2013). Global health 2035: a world converging within a generation. The Lancet, 382(9908), 1898-1955. https://doi.org/10.1016/S0140-6736(13)62105-4

Kann, L., McManus, T., Harris, W. A., Shanklin, S. L., Flint, K. H., Queen, B., ... \& Lim, C. (2018). Youth risk behaviour surveillance-United States, 2017. MMWR Surveillance Summaries, 67(8), 1-114. http://dx.doi.org/10.15585/mmwr.ss6708a1

Kaufman, M. R., Grilo, G., Williams, A., Marea, C. X., Fentaye, F. W., Abebe Gebretsadik, L., \& Yedenekal, S. A. (2019). The intersection of gender-based violence and risky sexual behaviour among university students in Ethiopia: a qualitative study. Psychology \& Sexuality, 11(3), 198-211.

https://doi.org/10.1080/19419899.2019.1667418

Kjellgren, C. (2019). Perspectives of young adult males who displayed harmful sexual behaviour during adolescence on motive and treatment, Journal of Sexual Aggression, 25(2), 116-130. https://doi.org/10.1080/13552600.2018.1563647

Lambie, I., \& Price, M. (2015). Transitioning youth with sexually harmful behaviour back into the community. Journal of Sexual Aggression, 21(2), 244-265. https://doi.org/10.1080/13552600.2013.873829

Lawal, A. M., \& Olley, B. O. (2017). Psychosocial factors predicting risky sexual behaviour among long distance truck drivers in Lagos, Nigeria. SAHARA-J: Journal of Social Aspects of HIV/AIDS, 14(1), 213-221. https://doi.org/10.1080/17290376.2017.1405838

Lin, Y. L., \& Lin, Y. C. (2018). Effectiveness of the sexual attitude restructuring curriculum amongst Taiwanese graduate students. Sex Education, 18(2), 140-156.

https://doi.org/10.1080/14681811.2017.1410698

Lincoln, Y. S., \& Guba, E.G. (1985). Naturalistic inquiry. SAGE. 
Meader, N., King, K., Moe-Byrne, T., Wright, K., Graham, H., Petticrew, M., ... \& Sowden, A. J. (2016). A systematic review on the clustering and co-occurrence of multiple risk behaviours. BMC Public Health, 16(1), 657. https://doi.org/10.1186/s12889-016-3373-6

Meho, L. I. (2006). E-mail interviewing in qualitative research: A methodological discussion. Journal of the American Society for Information Science and Technology, 57(10), 1284-1295. https://doi.org/10.1002/asi.20416

Mudhovozi, P. (2011). Unsafe Sexual Behaviour, Reasons for Consequences and Preventive Methods Among College Students. Journal of Psychology in Africa, 21(4), 573-575. https://doi.org/10.1080/14330237.2011.10820499

Nadal, K. L., Davidoff, K. C., Davis, L. S., Wong, Y., Marshall, D., \& McKenzie, V. (2015). A qualitative approach to intersectional microaggressions: Understanding influences of race, ethnicity, gender, sexuality, and religion. Qualitative Psychology, 2(2), 147. https://doi.org/10.1037/qup0000026

Ndumiso D. N., Sibusiso M., Thobile Z., Jamila K. A., \& Suresh B. N. K. (2016). Qualitative evaluation of selected social factors that impact sexual risk-taking behaviour among African students in KwazuluNatal, South Africa, SAHARA-J: Journal of Social Aspects of HIV/AIDS, 13(1), 96-105.

https://doi.org/10.1080/17290376.2016.1218792

Opdenakker, R. (2006). Advantages and disadvantages of four interview techniques in qualitative research. In Forum qualitative sozialforschung/forum: Qualitative Social Research, 7(4). Art. 11. http://nbn-resolving.de/urn:nbn:de:0114-fqs0604118.

Paiva, V., \& Silva, V. N. (2015). Facing negative reactions to sexuality education through a Multicultural Human Rights framework. Reproductive Health Matters, 23(46), 96-106. https://doi.org/10.1016/j.rhm.2015.11.015

Parker, R., Wellings, K., \& Lazarus, J. V. (2009). Sexuality education in Europe: An overview of current policies. Sex Education, 9(3), 227242. https://doi.org/10.1080/14681810903059060

Pringle, J., Mills, K. L., McAteer, J., Jepson, R., Hogg, E., Anand, N., \& Blakemore, S. J. (2017). The physiology of adolescent sexual 
200 Alonso-Martínez et al. - Sexual risk behaviours in young adults

behaviour: a systematic review. Cogent social sciences, 3(1), 1-14. https://doi.org/10.1080/23311886.2017.1368858

Public Health Agency of Canada. (2015). Report on sexually transmitted infections in Canada: 2012. Centre for Communicable Diseases and Infection Control, Government of Canada.

https://www.canada.ca/en/public-health/services/infectiousdiseases/surveillance-epidemiology-sexually-transmitted-infectionshep-b-c/report-2012/report-on-sexually-transmitted-infectionscanada-2012-8.html

Ratislavová, K., \& Ratislav, J. (2014). Asynchronous email interview as a qualitative research method in the humanities. Human Affairs, 24(4), 452-460. https://doi.org/10.2478/s13374-014-0240-y

Ruiz-Olabuénaga, J. I. (2012). Theory and practice of qualitative research. (5th ed.). Deusto University.

Schick, V., Herbenick, D., Reece, M., Sanders, S. A., Dodge, B., Middlestadt, S. E., \& Fortenberry, J. D. (2010). Sexual behaviours, condom use, and sexual health of Americans over 50: implications for sexual health promotion for older adults. The Journal of Sexual Medicine, 7(5), 315-329. https://doi.org/10.1111/j.17436109.2010.02013.x

Simon, W. (2017). Sexual conduct: The social sources of human sexuality. (2nd digital ed.). Routledge. https://doi.org/10.4324/9781315129242

Steadman, M., Crookston, B., Page, R., \& Hall, C. (2014). Parental attitudes regarding school-based sexuality education in Utah. American Journal of Sexuality Education, 9(3), 347-369.

https://doi.org/10.1080/15546128.2014.944737

Stevens, S., Thompson, E. M., Vinson, J., Greene, A., Powell, C., Licona, A. C., \& Russell, S. (2013). Informing sexuality education through youth-generated anonymous questions. Sex Education, 13(1), S84S98. https://doi.org/10.1080/14681811.2013.781020

UNESCO United Nations Educational, Scientific and Cultural Organization (2018). International technical guidance on sexuality education. An evidence informed approach (2nd digital ed.). UNESDOC. https://unesdoc.unesco.org/ark:/48223/pf0000260770

Wagenaar, C., Florence, M., Adams, S., \& Savahl, S. (2018). Factors influencing the relationship between alcohol consumption and risky sexual behaviour among young people: A Systematic Review. Cogent 
Psychology, 5(1), 1-26.

https://doi.org/10.1080/23311908.2018.1483049

WAS - World Association for Sexual Health (2014). Declaration of sexual rights. https://worldsexualhealth.net/wp-

content/uploads/2013/08/Declaration-of-Sexual-Rights-2014-plaintext.pdf

Walker, L. J. (2014). Sex differences in moral reasoning. In W.M. Kurtines, J. Gewirtz \& J.L. Lamb (Eds.), Handbook of moral behaviour and development, (pp.333-364). Taylor and Francis. https://doi.org/10.4324/9781315807287

World Health Organization. (2006). Defining sexual health: report of a technical consultation on sexual health.

https://www.who.int/reproductivehealth/publications/sexual_health/d efining_sh/en/

World Health Organization. (2019). Sexually transmitted infections (STIs). https://www. who.int/news-room/fact-sheets/detail/sexuallytransmitted-infections-(stis) 
Laura Alonso-Martínez is Predoctoral Fellow of the Department of Educational Sciences, Educational Faculty, University of Burgos, Spain. ORCID: 0000-0001-5425-5090

María Fernández-Hawrylak is Senior Lecturer of the Department of Educational Sciences, Educational Faculty, University of Burgos, Spain. ORCID: 0000-0002-7222-587X

Davinia Heras-Sevilla is Lecturer of the Department of Educational Sciences, Educational Faculty, University of Burgos, Spain. ORCID: 00000002-6337-7476

Delfín Ortega-Sánchez is Vice Chancellor for Social Responsibility, Culture and Sports and Senior Lecturer of the Department of Specific Didactics, Educational Faculty, University of Burgos, Spain. ORCID: 00000002-0988-4821

Contact Address: Laura Alonso-Martínez, Universidad de Burgos, Facultad de Educación, c/ Villadiego, 1, 09001 Burgos, España. Email: lamartinez@ubu.es 


\section{Annex 1}

\section{Interview Questions. Exploring Sexual Risk Behaviours in Young People}

\section{Sexual risk behaviour}

1. What is your understanding of the attitude and behaviour terms?

a) What behaviour and attitude do you consider of sexual risk? And which do you think happens more frequently?

b) What relation do you find between this concept and the age?

2. Could you explain what you think about the principal factors that influence people to take sexual risk behaviours?

a) Could you explain different factors by generation (adolescent, young adult, adult or older)?

b) Could you explain different factors by sex (adolescent, young adult, adult or older)?

3. Why do you consider that people have sexual risk behaviours?

4. What biologic and psychologic consequences do you think are derived from having sexual risk behaviours?

\section{Lived opinion and experiences about sexual risk behaviour}

5. What kind of programs do you think should be taught for avoiding this behaviour and in what age?

a) Why do you have this educational approach?

6. What would you advise a person who had to face sexual risk behaviours?

7. How would you improve sexuality education considering your experience?

\section{Closing the interview}

8. Anything I have missed that you think is important?

9. How long has it taken you to answer these questions?

Please do not hesitate to contact us if you have any questions

Will email you when the article was finished. 